\title{
DNA甲基化检测研究新进展
}

\section{冯福德, 王树}

中国科学院化学研究所, 北京 100190

* 联系人, E-mail: wangshu@iccas.ac.cn

哺乳动物 DNA 的甲基化几乎皆发生在 $\mathrm{CpG}$ 二核 甘酸的胞嘧啶上, 在基因调控区启动子上富含 $\mathrm{CpG}$ 序列, 而这些 $\mathrm{CpG}$ 序列的甲基化水平与基因的调控 和肿瘤的发生和发展有着极其重要的关系. 近年来, 随着聚合酶链式反应技术(PCR)的快速发展, 抑癌基 因的高甲基化与癌症的关系得到不断深入的研究. 与抑癌基因启动子区 $\mathrm{CpG}$ 岛的异常甲基化相关的抑 癌基因失活, 是癌症发生的一个重要机制. 一些基因 的过甲基化有可能成为肿瘤乃至癌细胞形成的标志 物. 在癌症早期了解相关抑癌基因启动子区 $\mathrm{CpG}$ 岛 的甲基化状态, 对于及时发现和治疗癌症具有重要 意义.

目前, 基因的甲基化研究主要结合亚硫酸氢钠 处理和PCR技术. 广泛应用的技术是Herman建立的 甲基化特异性的PCR技术(MSP) ${ }^{[1]}$ 和Jones建立的甲基 化敏感的单碱基延伸技术(Ms-SNuPE ${ }^{[2]}$ ，这两种方 法均以凝胶电泳为分析手段, 灵敏度和通量有限, 后 者还使用了有害的放射性同位素以提高灵敏度. 在 MSP技术的基础上, Laid发展了基于苂光检测方法的 实时定量PCR技术(MethyLight)，该技术具有较高的 检测灵敏度和通量 ${ }^{[3]}$. MethyLight技术需要使用双标 记的苂光探针DNA(Taqman探针), 这种探针与 PCR 产物匹配时被具有核酸外切酶活性的聚合酶降解而 出现苂光信号. 此外, Laid提出了依赖于限制性核酸 内切酶的甲基化分析方法(COBRA $)^{[4]}$. 这些方法
在一定程度上提高了特异性, 但是双标记苂光探针 价格较贵，且不易设计制备，另外检测依赖昂贵的实 时定量 PCR 仪.

共轭聚合物具有强的光捕获能力, 具有倍增光 学响应性, 可用来放大荧光传感信号, 为生物传感器 的发展提供了新的传感模式. 中国科学院化学研究 所与清华大学的研究人员合作, 发展了基于水溶性 阳离子型共轭聚合物的新DNA甲基化分析方法. 通 过苂光共振能量转移技术(FRET)研究了质粒和人肿 瘤细胞 $p 16$ 基因启动子区特异 $\mathrm{CpG}$ 位点的甲基化状态 (原理见图 1). 该技术具有较高的灵敏度和特异性, 引物无需苂光标记, 检测在均相溶液中进行, 无需分 离、纯化手段, 而且与高通量分析兼容, 在癌症临床 诊断上具有潜在的应用价值 ${ }^{[5]}$.

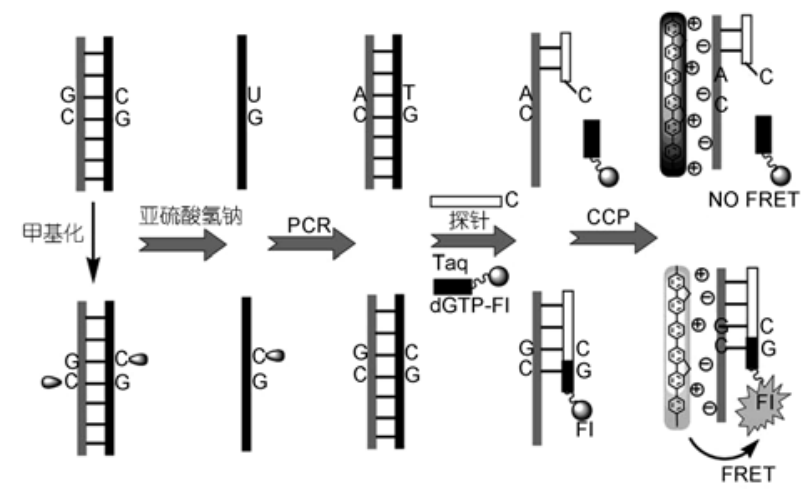

图 1 基于共轭聚合物的 DNA 甲基化检测原理

1 Herman J G, Graff J R S, Myohanen B D, et al. Baylin, Methylation-specific PCR: A novel PCR assay for methylation status of CpG islands. Proc Natl Acad Sci USA, 1996, 93: 9821-9826[doi]

2 Gonzalgo M L, Jones P A. Rapid quantitation of methylation differences at specific sites using methylation-sensitive single nucleotide primer extension (Ms-SNuPE).Nucleic Acids Res, 1997, 25: 2529-2531 [doi]

3 Eads C A, Danenberg K D, Kawakami K, et al. MethyLight: A high-throughput assay to measure DNA methylation. Nucleic Acids Res, 2000, 28: e32[doi]

4 Xiong Z, Laird P W. Cobra: A sensitive and quantitative DNA methylation assay. Nucleic Acids Res, 1997, 25: 2532-2534[doi]

5 Feng F, Wang H, Han Y, et al. Fluorescent conjugated polyelectrolyte as an indicator for convenient detection of DNA methylation. J Am Chem Soc, 2008, 130: 11338-11343[ㅇi] 